\title{
Non-melanoma skin cancer treated with high-dose- rate brachytherapy and Valencia applicator in elderly patients: a retrospective case series
}

\author{
Durim Delishaj!, Concetta Laliscia!, Bruno Manfredi', Stefano Ursino', Francesco Pasqualetti', Ezio Lombardo!, \\ Franco Perrone², Riccardo Morganti ${ }^{3}$, Fabiola Paiar', Maria Grazia Fabrinil \\ 'Department of Radiotherapy, ${ }^{2}$ Medical Physics, ${ }^{3}$ Section of Statistics, Azienda Ospedaliero Universitaria Pisana, University of Pisa, Pisa, Italy
}

\begin{abstract}
Purpose: The incidence of non-melanoma skin cancer (NMSC) has been increasing over the past 30 years. Basal cell carcinoma and squamous cell carcinoma are the two most common subtypes of NMSC. The aim of this study was to estimate tumour control, toxicity, and aesthetic events in elderly patients treated with high-dose-rate (HDR) brachytherapy (BT) using Valencia applicator.

Material and methods: From January 2012 to May 2015, 57 lesions in 39 elderly eligible patients were enrolled. All the lesions had a diameter $\leq 25 \mathrm{~mm}$ (median: $12.5 \mathrm{~mm}$ ) and a depth $\leq 4 \mathrm{~mm}$. The appropriate Valencia applicator, 2 or $3 \mathrm{~cm}$ in diameter was used. The prescribed dose was $40 \mathrm{~Gy}$ in 8 fractions (5 Gy/fraction) in 48 lesions (group A), and $50 \mathrm{~Gy}$ in 10 fractions (5 Gy/fraction) in 9 lesions (group B), delivered 2/3 times a week. The biological effective dose (BED) was 60 Gy and $75 \mathrm{~Gy}$, respectively.

Results: After median follow-up of 12 months, 96.25\% lesions showed a complete response and only two cases presented partial remission. Radiation Therapy Oncology Group - European Organization for Research and Treatment of Cancer (RTOG/EORTC) G 1-2 acute toxicities were observed in $63.2 \%$ of the lesions: $56.3 \%$ in group A and $77.7 \%$ in group B. Late G1-G2 toxicities was observed in $19.3 \%$ of the lesions: $18.8 \%$ in group A and $22.2 \%$ in group B, respectively. No G3 or higher acute or late toxicities occurred. In $86 \%$ of the lesions, an excellent cosmetic result was observed (87.5\% in group A and $77.8 \%$ in group B). Six lesions had a good cosmetic outcome and only $2.3 \%$ presented a fair cosmetic impact.

Conclusions: The treatment of NMSC with HDR-BT using Valencia surface applicator is effective with excellent and good cosmetics results in elderly patients. The hypofractionated course appears effective and no statistical differ-
\end{abstract} ences were observed between the two groups analysed.

J Contemp Brachytherapy 2015; 7, 6: 437-444 DOI: 10.5114/jcb.2015.55746

Key words: HDR brachytherapy, skin cancer, skin brachytherapy, Valencia applicator.

\section{Purpose}

The incidence of skin cancer has been increasing over the past 30 years and currently 2-3 million new cases are diagnosed worldwide every year. Non-melanoma skin cancer (NMSC) is the most common skin malignancy (95\%) and in recent years its incidence has been increasing rapidly, even in young populations [1, 2]. The development of NMSC is due to a combination of environmental, genetic, and phenotypic factors [3, 4]. Basal cell carcinoma (BCC) and squamous cell carcinoma (SCC) are the two most common subtypes: about $75-80 \%$ of all NMSC are characterized by the presence of BCC, $15-20 \%$ of these malignancies present SCCs, while $1 \%$ show a mixed phenotype [5]. There are different treatment options for NMSC such as surgery, cryotherapy, laser therapy (rec- ommended only for shallow and early SCC), topical chemotherapy, photodynamic therapy, and radiotherapy (RT). Surgical excision is the most frequent treatment due to its low rates of recurrence, reported less than $5 \%[6$, $7,8,9,10]$. In addition, RT is often used to treat NMSC and - specifically - different techniques can be used such as superficial $\mathrm{X}$-rays, electron beams, megavoltage photons, and low-dose-rate (LDR) or high-dose-rate (HDR) brachytherapy (BT). Usually, the treatment options are chosen based on the institutional resources and the specialist's experiences. The introduction of new devices usable with the equipment of HDR-BT and the commercialization of electronic BT has attracted considerable interest in the BT treatment of small skin tumours. The Valencia applicator (Nucletron, an Elekta company, Stockholm, Sweden) is a new superficial device used in BT to treat
Address for correspondence: Durim Delishaj, Department of Radiotherapy, Azienda Ospedaliero Universitaria Pisana, Via Roma 67, Pisa, Italy, phone: +39 050992829, fax: +39 050992960,

e-mail: delishaj@hotmail.com
Received: 06.08 .2015

Accepted: 22.10 .2015

Published: 30.12 .2015 
skin lesions, and has been projected to be used with the HDR afterloader microSelectron (Nucletron, an Elekta company, Stockholm, Sweden) [11, 12, 13, 14]. The design of Valencia applicators is based on Leipzig applicators, adding to them a flattening filter to improve the dose rate distributions' homogeneity and limit the penumbra. Regarding the dimensions, there are two sizes of Valencia applicators: $2 \mathrm{~cm}(\mathrm{VH} 2)$ and $3 \mathrm{~cm}(\mathrm{VH} 3)$ in diameter. The use of Valencia applicators is recommended for superficial tumours (less than $4 \mathrm{~mm}$ depth) with a maximum diameter of $25 \mathrm{~mm}$ due to guaranteeing adequate tumour coverage. The reinforced shielding at the back of the skin radiation applicator adds to patient safety during treatment, and plastic caps on the applicator help to avoid over-dosage and assist with correct applicator positioning $[11,12,13]$. The design of this applicator allows us to focus the radiation on the target while normal tissue irradiation is minimized, leading to safer treatment and

Table 1. Patients and lesion characteristics

\begin{tabular}{|c|c|c|}
\hline Demographics & Number & $\%$ \\
\hline \multicolumn{3}{|l|}{ Patient characteristics } \\
\hline \multicolumn{3}{|l|}{ Age (years) } \\
\hline Median & 84 & \\
\hline Minimum & 70 & \\
\hline Maximum & 96 & \\
\hline \multicolumn{3}{|l|}{ Sex } \\
\hline Male & 24 & 61 \\
\hline Female & 15 & 39 \\
\hline \multicolumn{3}{|l|}{ Histology } \\
\hline Basal cell carcinoma & 44 & 77.2 \\
\hline Squamous cell carcinoma & 12 & 21.1 \\
\hline Kaposi's sarcoma & 1 & 1.7 \\
\hline \multicolumn{3}{|l|}{ Lesion diameter (mm) } \\
\hline Minimum & $3 \mathrm{~mm}$ & \\
\hline Maximum & $25 \mathrm{~mm}$ & \\
\hline Median & $12.5 \mathrm{~mm}$ & \\
\hline \multicolumn{3}{|l|}{ Lesion location } \\
\hline Head and Neck & 46 & 80.7 \\
\hline Scalp & 18 & 31.6 \\
\hline Face & 15 & 26.3 \\
\hline Nose & 8 & 14 \\
\hline Ear & 3 & 5.3 \\
\hline Neck & 2 & 3.5 \\
\hline Trunk & 7 & 12.3 \\
\hline Extremity & 4 & 7 \\
\hline
\end{tabular}

a decrease in side effects in normal tissue $[11,12,13,14$, $15,16,17,18,19,20,21,22,23,24]$.

The aim of this study was to retrospectively estimate tumour control, toxicity, and cosmetic events in two case series of elderly patients, affected by NMSC treated with HDR BT using a Valencia applicator.

\section{Material and methods}

\section{Patients' eligibility}

We retrospectively evaluated 57 lesions in 39 elderly patients treated with HDR-BT using a Valencia applicator. All the patients presented NMSC (confirmed by histological examination) and were treated at the Department of Radiotherapy, University of Pisa. All the enrolled patients were older than 70 years. Patients aged less than 70 years with a diagnosis of melanoma were excluded from the study; patients showing diameter lesions greater than $25 \mathrm{~mm}$ and a depth of more than $4 \mathrm{~mm}$ by clinical and imaging evaluation were also excluded. In this study, NMSC patients who were surgically treated or who had relapses or recidivisms were also included.

Furthermore, any patients who were unable to collaborate and stayed fixed during the treatment were excluded from the study. The cohort's characteristics are shown in Table 1 and a consort flow diagram is shown in Figure 1.

\section{Treatment procedure}

All the lesions for the selected cases were limited to a maximum depth of $4 \mathrm{~mm}$ and a diameter equal to or less than $25 \mathrm{~mm}$. This limitation was necessary to keep the skin dose at acceptable levels because the percentage depth dose of the ${ }^{192} \mathrm{Ir}$ Valencia applicators has a gradient of about $10 \%$ per $\mathrm{mm}$ [14]. The planning target volume

69 lesions in 51 pts affected

by NMSC candidate at tratment with HDR-BT using Valencia applicatiors were analyzed

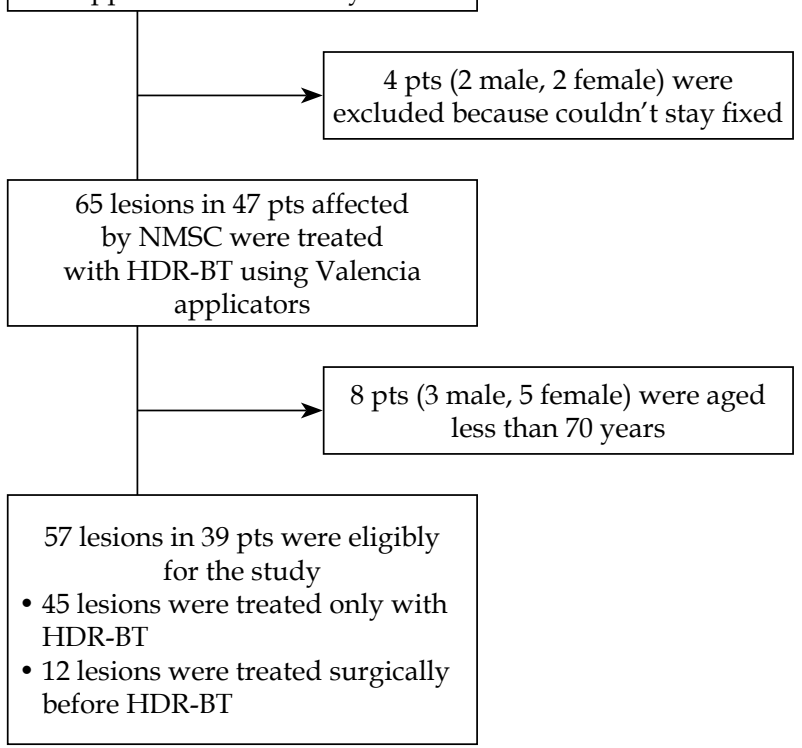

Fig. 1. Consort flow diagram 
was defined as a BCC and SCC macroscopic lesion (gross tumour volume) adding an adequate margin of $5 \mathrm{~mm}$. According to Brodland et al.'s [8] data and based on the other HDR-BT studies [18, 19, 20, 23, 24, 25, 26, 27, 28, $29,30,31,32,33,34,35,36]$, a margin of $5 \mathrm{~mm}$ for BCC and SCC lesions appears to be adequate. The maximal diameter able to be treated using Valencia applicators is $25 \mathrm{~mm}$, since the largest surface applicator has an inner diameter of $30 \mathrm{~mm}$. This is possible due to improvements in the lateral homogeneity and flatness of the Valencia applicator compared to the Leipzig applicators. The values of the penumbra (80-20\%) are significantly improved from the Leipzig $(6.2-9.5 \mathrm{~mm})$ to the Valencia applicators $(1.9 \mathrm{~mm})$. As such, the useful treatment area of the Valencia applicator is larger and this allows a $5 \mathrm{~mm}$ margin for microscopic diseases and set-up errors in lesions with a diameter $\leq 25 \mathrm{~mm}[11,12,14]$. The gross tumour volume (GTV) was generally visually assessed; however, ultrasound imaging or a CT scan were, in a few cases ( $n=7$ lesions), used to determine the real depth and lesion dimensions. An appropriate Valencia applicator -2 or 3 $\mathrm{cm}$ of diameter - was chosen based on the diameter lesion for an optimal dose rate distribution to the GTV [14, 21]. The treatment dose prescription was $40 \mathrm{~Gy}$ in eight fractions (5 Gy for each fraction daily) in 48 lesions (group A) and 50 Gy in 10 fractions (5 Gy for each fraction daily) in nine lesions (group B). The total dose was chosen based on the lesion dimensions, age, and performance status. The dose prescription was delivered as two/three fractions a week, with a minimum interval of 48 hours between fractions. The treatment characteristics are shown in Table 2.

The Biological Effective Dose (BED) was (BED a $/ \beta: 10$ ) $60 \mathrm{~Gy}$ in group A and (BED $\alpha / \beta: 10) 75 \mathrm{~Gy}$ in group B. All the patients were immobilized during the treatment and a skin marker delineating the outside applicator circumference was used in some patients to ensure reproducible treatment conditions. The immobilization was achieved in some cases (such as patients with head and neck lesions) using an articulated arm device provided by $\mathrm{Nu}$ cletron; in less difficult cases, the methods of immobilization were tape or a thermoplastic mask. The treatment was effectuated under the direct supervision of the radiation oncologist for accurate applicator positioning and dose delivery. As a precaution, it was recommended for

Table 2. Treatment characteristics

\begin{tabular}{lccc}
\hline Treatment characteristics & $\begin{array}{c}\text { Number } \\
\text { of lesions }\end{array}$ & BCC & $\begin{array}{l}\text { SCC and } \\
\text { Kaposi's } \\
\text { sarcoma }\end{array}$ \\
\hline \begin{tabular}{l} 
Total dose (Gy; BED $\alpha / \beta: 10)$ \\
\hline 50 Gy $\left(\mathrm{BED}_{75}\right)$
\end{tabular} & $9(16 \%)$ & 6 & 3 \\
\hline 40 Gy $\left(\mathrm{BED}_{60}\right)$ & $48(84 \%)$ & 38 & 10 \\
\hline Applicator size $(\mathrm{mm})$ & $28(49 \%)$ & 20 & 8 \\
\hline Valencia 20 & $29(51 \%)$ & 24 & 5
\end{tabular}

$B E D$ - biological effective dose, BCC - basal cell carcinoma, SCC - squamous cell carcinoma all patients to not wear any make-up and in addition they were continuously monitored during treatment by video camera and audio connection with a treatment room to ensure the immobility of the patient.

\section{End points}

The end points chosen for this study were analysis of efficacy, safety, toxicity, and cosmetic outcomes in elderly patients treated with HDR-BT using Valencia applicators. Acute and chronic toxicities were evaluated in both groups according to the Radiation Therapy Oncology Group (RTOG) and the European Organization for Research and Treatment of Cancer (EORTC) scales by clinical evaluation during and after treatment. The cosmetic results were estimated at each follow-up visit based on the radiation therapy oncology group scale (Table 3) [25].

\section{Results}

\section{Patient and treatment characteristics}

Between January 2012 and May 2015, 57 lesions in a total of 39 patients affected by NMSC were treated with HDR-BT using a Valencia surface applicator. Of them, 25 patients $(61 \%)$ were male and $14(39 \%)$ were female. Twelve lesions were treated as a supplementary therapy after surgery treatment (Figure 1). The median age of the patients treated was 84 years (DS \pm 7.84 ) with a wide range from 70 to 96 years. Most of lesions (77.2\%) histologically were BCC: $21.1 \%$ were SCC and one lesion was Kaposi's sarcoma. In addition, 46 lesions $(80.7 \%)$ were located on the head and the neck: seven lesions $(12.3 \%)$ on the trunk, and four lesions $(7 \%)$ were found on the extremities. The median diameter of the lesion was $12.5 \mathrm{~mm}$ (range: $3-25$ ) and all lesions had a depth of less than $4 \mathrm{~mm}$. Table 1 describes the patient and lesion characteristics. During the treatment, we used 29 applicators with a diameter of $3 \mathrm{~cm}$ and 28 applicators with a diameter of $2 \mathrm{~cm}$, as shown in Table 2 . The median follow-up was 12 months (range: 3-29 months).

\section{Efficacy}

After 12 months median follow-up, 55 lesions (96.5\%) completely regressed and only two lesions persisted: one lesion was histologically diagnosed as SCC, located in

Table 3. Cosmetic rating scale [25]

\begin{tabular}{ll} 
Excellent & $\begin{array}{l}\text { No changes to slight atrophy or pigment change or } \\
\text { slight hair loss or no changes to slight induration } \\
\text { or loss of subcutaneous fat }\end{array}$ \\
\hline Good & $\begin{array}{l}\text { Patch atrophy, moderate telangiectasia, and total } \\
\text { hair loss; moderate fibrosis but asymptomatic; } \\
\text { slight field contracture with less than 10\% linear } \\
\text { reduction }\end{array}$ \\
\hline Fair & $\begin{array}{l}\text { Marked atrophy and gross telangiectasia; severe } \\
\text { induration or loss of subcutaneous tissue; field } \\
\text { contracture greater than 10\% linear measurement }\end{array}$ \\
\hline Poor & Ulceration or necrosis
\end{tabular}


Table 4. Results

\begin{tabular}{lccc} 
& All lesions & $\begin{array}{c}\text { Group A } \\
\text { (40 Gy in 8 faction) }\end{array}$ & $\begin{array}{c}\text { Group B } \\
\text { (50 Gy in 10 fraction ) }\end{array}$ \\
\hline Response to treatment & $55(96.25 \%)$ & 47 & 1 (SCC) \\
\hline Complete response & $2(3.5 \%)$ & 1 (BCC) & 0 \\
\hline Partial response & 0 & 0 & $7(77.7 \%)$ \\
\hline Recurrence & $36(63.2 \%)$ & $29(60.4 \%)$ & $6(66.7)$ \\
\hline Acute toxicity & $33(58 \%)$ & $27(56.3 \%)$ & $1(11.1 \%)$ \\
\hline Grade 1 & $3(5.3 \%)$ & $2(4.1 \%)$ & 0 \\
\hline Grade 2 & 0 & 0 & $2(22.2 \%)$ \\
\hline Grade 3 & $11(19.3 \%)$ & $9(18.8 \%)$ & 0 \\
\hline Late toxicities & $10(17.5 \%)$ & $1(22.2 \%)$ \\
\hline Grade 1 & $1(1.9 \%)$ & 0 & 0 \\
\hline Grade 2 & 0 & $42(87.5 \%)$ & 0 \\
\hline Grade 3 & $1(1.7 \%)$ & $5(10.4 \%)$ & $7(77.8 \%)$ \\
\hline Cosmetic results & 0 & $1(2.1 \%)$ & $2(22.2 \%)$ \\
\hline Excellent & $49(86 \%)$ & 0 & 0 \\
\hline Good & $7(12.3 \%$ & & 0 \\
\hline Pair & & & 0 \\
\hline
\end{tabular}

the trunk, and received a total dose of 50 Gy delivered in 10 fractions. The second lesion was instead diagnosed as $\mathrm{BCC}$, and it was located in the face, treated with a total dose of $40 \mathrm{~Gy}$ in eight fractions. In both lesions, the depth of the lesion was less than $4 \mathrm{~mm}$ and the tumour diameter was less than $25 \mathrm{~mm}$. No recurrences or disease persistence were detected during the follow-up and there was no difference between the two groups (Table 4).

\section{Adverse events and cosmetic results}

The treatment was well tolerated in all cases. The most common early side-effects were erythema, rash dermatitis, and pruritus, which occurred in $63.2 \%$ of the patients. The highest skin acute toxicity was Grade 1 RTOG/EORTC [25] and occurred in 58\% of the lesions: $56.3 \%$ of the lesions in group A and $66.7 \%$ of the lesions in group B. Only three $(5.3 \%)$ lesions had Grade 2 toxicities: $4.1 \%$ in group A and $11.1 \%$ in group B. All the cases of G1-G2 acute toxicity were resolved with topical treatment. No statistically differences were observed between the two groups analysed regarding acute toxicities $(p=0.269)$.

On the subject of late toxicities, there were 11 cases of G1G2 late toxicities: G1 was observed in $16.7 \%$ of the lesions in group A and 22.2\% of the lesions in group B. Only one case of G2 late toxicity in group A was observed. They were all resolved with adequate local treatment and no statistical differences existed between the two groups $(p=0.404)$. There were no Grade 3 or higher acute or late toxicities.

The cosmetic results were evaluated at each follow-up visit based on the radiation therapy oncology group scale
(Table 3) [25]. An excellent cosmetic result was observed in $86 \%$ of lesions: $87.5 \%$ in group A and $77.8 \%$ in group B (Table 4 results; Figure 2).

About $12.3 \%$ of the lesions had good cosmetic results (moderate atrophy in three patients and moderate asymptomatic fibrosis in another four): five (10.4\%) in group A and two $(22.2 \%)$ in group B.

Only one patient $1.7 \%$ (in group A) presented a fair cosmetic result. There was no correlation between the two groups and excellent cosmetic results $(p=0.458)$. Finally, there were no cases of poor cosmetic results.

With univariate statistical analysis of local control prognostic factors, only the total dose prescribed was statistically significant $(p=0.001)$, leading to improve local control. This means that with increasing the total dose - with an equal dose for fractions - local control probability is improved. Other prognostic factors at regression univariate analysis, such as lesion dimensions, histology, and surgery did not lead to improved disease local control (Table 5).

The statistical analyses data were performed with SPSS version 22 (SPSS Inc. SPSS ${ }^{\circledR}$ Chicago, IL, USA). All the variables were described by statistical characteristics: categorical data were described by frequency and percentage, whereas continuous data were described by mean and range. The study of local control prognostic factors such as lesion dimensions, histology type, surgery, and total dose was performed through the use of a univariate generalized linear model. The results of the regression model were calculated by a Wald test and 

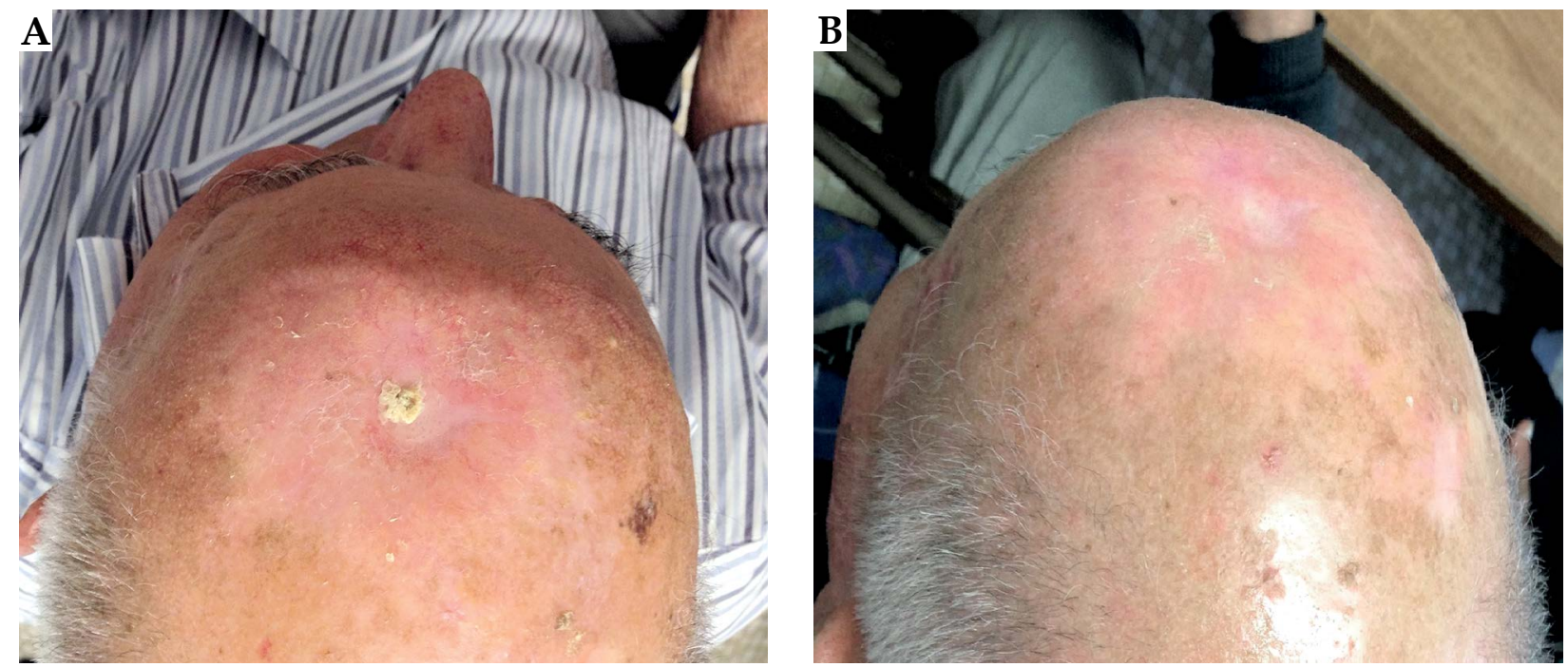

Fig. 2. An example of complete response (B) after nine months of treatment of NMSC with HDR-BT using a Valencia applicator

Table 5. Univariate analysis of local control prognostic factors

\begin{tabular}{lcccc} 
Factor & Intercept & $\mathrm{B}^{*}$ & Wald test & $p$ value \\
\hline Lesion dimension (3-25 mm) & 11,663 & $-0,31$ & 0,034 & 0,854 \\
\hline Histology (SCC, SCC, Kaposi's sarcoma) & 11,949 & $-1,656$ & 2,015 & 0,156 \\
\hline Surgery (yes, no) & 8,484 & 2,044 & 1,062 & 0,303 \\
\hline Total dose (40 Gy, 50 Gy) & 10,021 & 7,979 & 10,799 & 0,001
\end{tabular}

*Regression coefficient; BCC - basal cell carcinoma, SCC - squamous cell carcinoma

expressed using the regression coefficients. Differences were considered significant at $p<0.05$.

\section{Discussion}

Surgery is often the primary treatment for NMSC lesions for the low rates of recurrence reported $[6,7,8$, $9,10]$. However, surgical treatment is an invasive procedure and in elderly patients is not always feasible because of comorbidities, performance status, or lesion location (near the eyes, nose, and on facial skin). Typically, RT is the treatment of choice in this class of patients since surgery might be accompanied with functional or cosmetic deficits. The development of new devices for small skin tumour treatment and the introduction of commercial electronic BT, have attracted considerable interest for BT as a skin cancer treatment. Despite the new technologies available, few studies have focused on the treatment of NMSC with HDR-BT. Köhler et al. [13] in 1999 described the outcome of 520 lesions treated with HDR-BT using Leipzig applicators. The dose prescribed was 30-40 Gy in 5-10 fractions, and after 10 years follow-up local control was $92 \%$ of the cases; only G1-G2 late and acute toxicities were observed. In the study was included Kaposi's sarcoma, melanomas, and skin metastases. One year later, Guix et al. [24] reported the results of 236 NMSC lesions treated with HDR-BT using custom-made surface moulds. At five years median follow-up, local control was $98 \%$. In ad- dition, Gauden et al. [31] published the data of 236 lesions using Leipzig applicators. The total dose prescribed was $36 \mathrm{~Gy}$ in 12 fractions and the local control was $98 \%$ after 36 months follow-up. No G3 or higher late or acute toxicities were observed. Recently, Bhatnagar et al. [32] and Tormo et al. [36] published the results of a hypofractionated course (using Valencia applicators and HDR electronic BT with surface applicators, respectively), which resulted in excellent local control, cosmetic results, and very lowgrade toxicities after a median follow-up of 47 months and 12 months, respectively. Table 6 describes some previous studies of HDR-BT for NMSC.

We showed in our study that the treatment of 57 NMSC lesions with HDR-BT using Valencia surface applicator with doses of 50 Gy and 40 Gy in 10 and eight fractions is effective and safe in elderly patients. In this study, the BED was evaluated and in particular the BED values were BED 60 in group A and BED 75 in group B. Biological effective dose is an inherent part of the linear quadratic (LQ) model of radiation effects, and estimates the true biological dose delivered by a particular combination of dose per fraction and total dose to a given tissue characterized by a specific $a / b$ ratio. It is calculated by the equation $\mathrm{BED}=$ nd $[1+\mathrm{d}(\mathrm{a} / \beta)]$, where $n=$ the number of fractions, $d=$ the dose/fraction, and $a / \beta=$ radio-sensitivity coefficients at the dose at which the linear and quadratic components (for early or late cell damage, respectively) of cells killed are equal [33, 34]. 


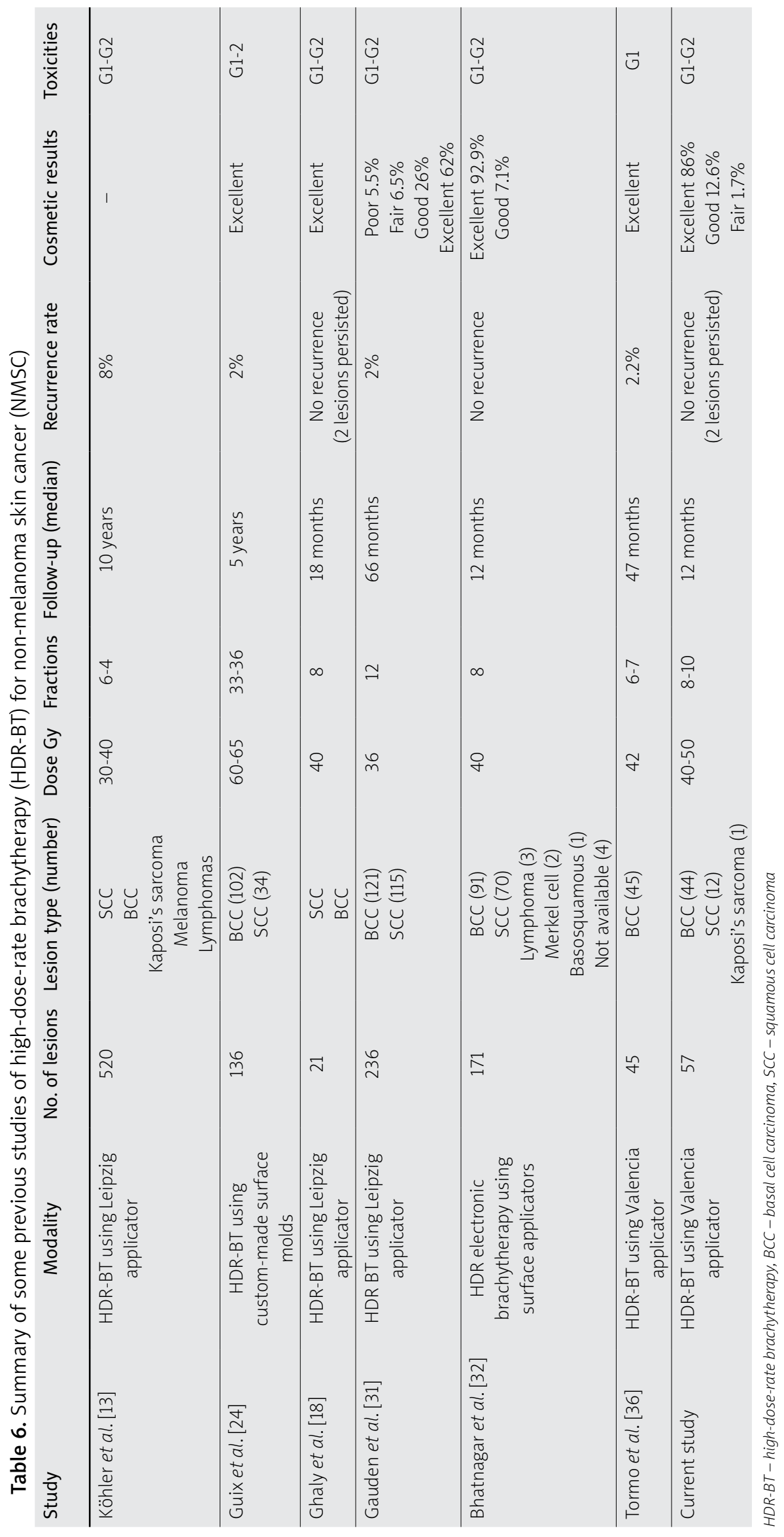


The $a / b$ ratios vary based on the tumour type. For example, squamous cell cancers with high cell proliferation are characterized by $10-30 \mathrm{\alpha} / \beta$ ratio, while breast cancer shows lower values (4-5 Gy) [34] as well in prostate cancer (0.8-2.5 Gy) [35] and melanoma malignancies [34]. For NMSC, the alpha/beta ratios are approximately 10 Gy [34]. From the previous equation, it is evident that the BED will increase proportionally to the dose per fraction and inversely proportional to the $\alpha / \beta$ ratio. If the total dose is kept constant, the BED will increase if the dose per fraction is increased [33, 34, 35]. For these reasons, it is important to perform BED calculations before clinical decisions since different histological classes of cancers have different $\mathrm{a} / \mathrm{b}$ ratios, leading to different clinical responses, despite the total dose not change. The hypofractionated course (40-50 Gy in 8-10 fractions delivered two/three time a week with a minimum interval of 48 hours between fractions) appears to be effective with very good local control, excellent cosmetic results, and acceptable toxicities in elderly patients. No recurrences after 12 months follow-up have been observed at the time of the analysis, and overall, the treatment was very well tolerated with no evidence of Grade 3 or higher toxicities.

The limitation of this study compared with studies of more established treatments for NMSC was the relatively short follow-up and small number of patients due to the age of the patients (mean age 84 years) aa well as comorbidities. In particular, patients exhibited a low life expectancy and important comorbidities such as cardiovascular and pulmonary complications (due to age rather than therapy), which did not allow a long follow-up in all patients. Non-melanoma skin cancer patients will continue to be followed and additional patients will be enrolled for further study of the outcomes using HDR-BT.

\section{Conclusions}

In our study, the treatment of NMSC with HDR-BT using Valencia surface applicator was effective and safe in elderly patients. After 12 months follow-up, no recurrences were observed and the treatment was very well tolerated with no Grade 3 or higher acute or late toxicities. In addition, we found excellent and good cosmetics results. Valencia applicators provide a simple, safe, quick, and easy alternative for skin cancer treatment compared with more invasive methods, such as surgery or cryotherapy, in this subset of patients. Overall, the hypofractionated course appears effective with very good local disease control; moreover, this cost effective therapy shows high compliance and a feasible outpatient treatment regimen, essential in elderly patients. No statistical differences were observed between the two groups analysed regarding efficacy, acute toxicities, late toxicities, and cosmetic results.

\section{Acknowledgments}

The authors declare that an abstract with preliminary data (a total of 52 lesions) has been accepted as a poster (abstract number 3316 ) at $18^{\text {th }} \mathrm{ECCO}-40^{\text {th }}$ ESMO European Cancer Congress held in Vienna, Austria, $25^{\text {th }}-29^{\text {th }}$ September 2015.

\section{Disclosure}

Authors report no conflict of interest.

\section{References}

1. Lomas A, Leonardi-Bee J, Bath-Hextall F. A systematic review of worldwide incidence of nonmelanoma skin cancer. Br J Dermatol 2012; 166: 1069-1080.

2. Eisemann N, Waldmann A, Geller AC et al. Non-melanoma skin cancer incidence and impact of skin cancer screening on incidence. J Invest Dermatol 2014; 134: 43-50.

3. Kricker A, Armstrong BK, English DR et al. Does intermittent sun exposure cause basal cell carcinoma. A case-control study in Western Australia. Int J Cancer 1995; 60: 489-494.

4. Rosso S, Zanetti R, Martinez C et al. The multicentre south European study 'Helios'. I: Different sun exposure patterns in the aetiology of basal cell and squamous cell carcinomas of the skin. Br J Cancer 1996; 73: 1440-1446.

5. Katalinic A, Kunze U, Schafer T. Epidemiology of cutaneous melanoma and non-melanoma skin cancer in Schleswig-Holstein, Germany: incidence, clinical subtypes, tumour stages and localization (epidemiology of skin cancer). $\mathrm{Br}$ J Dermatol 2003; 149: 1200-1206.

6. Caresana G, Giardini R. Dermoscopy-guided surgery in basal cell carcinoma. J Eur Acad Dermatol Venereol 2010; 24: 1395-1399.

7. Smeets NW, Kuijpers DI, Nelemans P et al. Mohs' micrographic surgery for treatment of basal cell carcinoma of the face - results of a retrospective study and review of the literature. Br J Dermatol 2004; 151: 141-147.

8. Brodland DG, Zitelli JA. Surgical margins for excision of primary cutaneous squamous cell carcinoma. J Am Acad Dermatol 1992; 27: 241-248.

9. Macfarlane L, Waters A, Evans A et al. Seven years' experience of Mohs micrographic surgery in a UK centre, and development of a UK minimum dataset and audit standards. Clin Exp Dermatol 2013; 38: 262-269.

10. Chren MM, Torres JS, Stuart SE et al. Recurrence after treatment of non melanoma skin cancer: a prospective cohort study. Arch Dermatol 2011; 147: 540-546.

11. Pérez-Calatayud J, Granero D, Ballester F et al. A dosimetric study of the Leipzig applicators. Int J Radiat Oncol Biol Phys 2005; 62: 579-584.

12. Niu H, Hsi WC, Chu JC et al. Dosimetric characteristics of the Leipzig surface applicators used in the high dose rate brachy radiotherapy. Med Phys 2004; 31: 3372-3327.

13. Köhler-Brock A, Prager W, Pohlmann S et al. The indications for and results of HDR afterloading therapy in diseases of the skin and mucosa with standardized surface applicators (the Leipzig Applicator). Strahlenther Onkol 1999; 175: 170-174.

14. Granero D, Perez-Calatayud J, Ballester F et al. Radiation leakage study for the Valencia applicators. Phys Med 2013; 29: 60-64.

15. Granero D, Pérez-Calatayud J, Gimeno J et al. Design and evaluation of a HDR skin applicator with flattening filter. Med Phys 2008; 35: 495-503.

16. Kowalik L, Lyczek J, Sawicki M et al. Individual applicator for brachytherapy for various sites of superficial malignant lesions. J Contemp Brachytherapy 2013; 5: 45-49.

17. Hwang IM, Lin SY, Lin LC et al. Alternative effective modality of Leipzig applicator with an electron beam for the treatment of superficial malignancies. Nuc Inst Meth A 2003; 508: 460-466.

18. Ghaly M, Birnes R, Musmacher J et al. HDR brachytherapy with standardized surface applicators (the Leipzig applicator) as an alternative, radiotherapy treatment for superficial malignant skin lesions. Int J Radiat Oncol Biol Phys 2006; 66: S719-S720. 
19. Svoboda V, Kovarik J, Morris F. High dose-rate microselectron molds in the treatment of skin tumors. Int J Radiat Oncol Biol Phys 1995; 31: 967-972.

20. Ghaly M, Zinkin H, Dannenberg M et al. HDR brachytherapy with Standardized Surface Applicators in the Treatment of Superficial Malignant Skin Lesions. Int J Radiat Oncol Biol Phys 2008; 72: S505-S506.

21. Khan L, Choo R, Breen D et al. Recommendations for CTV margins in radiotherapy planning for non melanoma skin cancer. Radiother Oncol 2012; 104: 263-266.

22. Lovett RD, Perez CA, Shapiro SJ et al. External radiation of epithelial skin cancer. Int J Radiat Oncol Biol Phys 1990; 19: 235-242.

23. Alam M, Nanda S, Mittal BB et al. The use of brachytherapy in the treatment of nonmelanoma skin cancer: a review. J Am Acad Dermatol 2011; 65: 377-388.

24. Guix B1, Finestres F, Tello J et al. Treatment of skin carcinomas of the face by high dose rate brachytherapy and custom made surface molds. Int J Radiat Oncol Biol Phys 2000; 47: 95102.

25. Cox JD, Stetz J, Pajak TF. Toxicity criteria of the Radiation Therapy Oncology Group (RTOG) and the European Organization for Research and Treatment of Cancer (EORTC). Int J Radiat Oncol Biol Phys 1995; 31: 1341-1346.

26. Fabrini MG, Perrone F, De Liguoro M et al. High dose rate brachytherapy in a large squamous cell carcinoma of the hand. Brachytherapy 2008; 7: 270-275.

27. Ballester-Sánchez R, Pons-Llanas $\mathrm{O}$, Llavador-Ros $\mathrm{M}$ et al. Depth determination of skin cancers treated with superficial brachytherapy: ultrasound vs. histopathology. J Contemp Brachytherapy 2015; 6: 356-361.

28. Montero A, Hernanz R, Capuz AB et al. High-dose-rate (HDR) plesiotherapy with custom-made moulds for the treatment of non-melanoma skin cancer. Clin Transl Oncol 2009; 11: 760-764.

29. Maroñas M, Guinot JL, Arribas L et al. Treatment of facial cutaneous carcinoma with high dose rate contact brachytherapy with customized molds. Brachytherapy 2011; 10: 221-227.

30. Kanikowski M. HDR brachytherapy of skin cancer in material of Greater Poland Cancer Center. J Contemp Brachytherapy 2009; 1: 197 (Abstract).

31. Gauden R, Pracy M, Avery AM et al. HDR brachytherapy for superficial non-melanoma skin cancers. Radiat Oncol 2013; 57: 212-217.

32. Bhatnagar A. Nonmelanoma skin cancer treated with electronic brachytherapy: results at 1 year. Brachytherapy 2013; 12: $134-140$.

33. Jones B, Dale RG, Deehan C et al. The role of biologically effective dose (BED) in clinical oncology. Clin Oncol (R Coll Radiol) 2001; 13: 71-81.

34. Jones B, Dale RG. Mathematical models of tumour and normal tissue response. Acta Oncol 1999; 38: 883-893.

35. Brenner DJ, Hall EJ. Fractionation and protraction for radiotherapy of prostate cancer. Int J Radiat Oncol Biol Phys 1999; 43: 1095-1101.

36. Tormo A, Celada F, Rodriguez $\mathrm{S}$ et al. Non-melanoma skin cancer treated with HDR Valencia applicator: clinical outcomes. J Contemp Brachytherapy 2014; 6: 167-172. 